\title{
Where Is the Unbiased Information?
}

\author{
Vinjar Magne Fønnebø
}

National Research Center in Complementary and Alternative Medicine (NAFKAM), University of Tromsø, Tromsø, Norway

Complementary medicine and cancer is a challenging and complicated topic for patients and their loved ones as well as for alternative practitioners, oncologists, and family physicians. The diagnosis is often associated with imminent death or a prolonged phase of suffering from both the disease and its aggressive surgical, chemotherapeutic, or radiological treatment.

Patients and their families are often desperately seeking several opinions, thereby hoping that someone has found the magic bullet. Their search leads them both to conventional experimental treatments as well as complementary and alternative treatments. The search has no longer any geographical limits [1], and the treatment costs are rarely a major concern.

In this medical market situation, there is a wide open entrance door for treatment providers of all shades to offer different approaches, sometimes at a high cost. Germany has its 'Germanische Neue Medizin' (www.neue-medizin.de), Denmark had its 'Humlegaarden', and Poland had the Santa Monica Clinic which has relocated to Sweden (www.santamonica.se). Further away, the border town of Tijuana in Mexico has a number of clinics and other health care institutions, such as the famous Gershon Clinic (https:// gerson.org/gerpress/gerson-clinic-mexico/).

Family doctors and oncologists in conventional medicine are often appalled by these alternative practices. They see these treatment providers as cynical opportunists encouraging vulnerable individuals to abandon conventional care and offering them cancer cure, disregarding any documentation whatsoever. On top of that, they are accused of charging unreasonably high fees. The doctors' opinions may well be based on own experience with previous cancer patients, not so much on current evidence in these treatment areas.

Cancer patients have considerable problems when faced with these conflicting opinions. Most might want sound advice from the family doctor or trusted oncologist, but are hesitant in bringing up these subjects in the consultation. They are afraid of being perceived as ignorant or ungrateful and feel uncomfortable given the idea of being potentially confronted with condescending attitudes from their physicians [2]. As a consequence, their search for alternatives continues, surrounded by information from providers of dietary supplements and practitioners of complementary medicine promising them alternative treatments for cancer.

In this heated and confusing situation alternative practitioners, healthcare personnel, other patients as well as their friends and families desperately need plain, trustable information.

To meet this desperate need, the 'Concerted Action for Complementary and Alternative Medicine Assessment in the Cancer Field' (CAM-CANCER) has been developed (www.cam-cancer.org). CAM-CANCER was initiated by the Swiss Cancer League and obtained funding from 2002 to 2005 under the 'Fifth Framework Programme' in the EU research system. The initiative resulted in several deliverables, with 'CAM Summaries' as the most successful outcome. These summaries are related to systematic reviews, but are more compact, developed through a stringent and transparent editorial process. As with many other short-term funded projects, however, the activity stopped when the EU funding was over. The original project partners moved on to other projects and the important efforts seemed to be wasted.

But this time the story luckily did not end here. The CAMCANCER 'brand' has been taken over by the National Research Center in Complementary and Alternative Medicine (NAFKAM) at UiT, the Arctic University of Norway in Tromsø, Norway, and is now an integral part of the center's information service to Norwegian MDs. The language is still English and the information targets therefore also an international audience.

Although this story seems to end well, it illustrates a major problem with regard to international funding of both research and information in CAM. Industry-independent research and information in this area of health care is even more uncommon than in conventional medicine. To make matters even worse, only very few academic and/or governmental institutions in Europe have a sustainable long-term funding situation. This is one of the most important obstacles to academically independent research as well as high-quality patient and provider information.

\section{KARGER}

Fax +497614520714
() 2015 S. Karger GmbH, Freiburg

$1661-4119 / 15 / 0226-0356 \$ 39.50 / 0$
Vinjar M. Fønnebø, MD, MSc, PhD

National Research Center in Complementary and Alternative Medicine (NAFKAM) University of Tromse

9037 Tromsø, Norway

vinjar.fonnebo@uit.n。 
CAM-CANCER provides a world-wide access to tailored and high-quality English-language information on CAM approaches and cancer. But as an international community, Europe can do better than that!

\section{References}

1 Fønnebø V, Verhoef M, Paterson C: Cancer and complementary medicine: an international perspective. Support Care Cancer 2007;15:999-1002.

2 Salamonsen A: Doctor-patient communication and cancer patients' choice of alternative therapies as supplement or alternative to conventional care. Scand J Caring Sci 2013;27:70-76. 